Although there is some overlap between the two sets of proposals, they have very different implications. It is therefore essential that we respond to them separately. It is perfectly logical-and probably politically more effective - to oppose one but not the other.

The white paper is about fundamental changes to the NHS as a whole. It has no clear commitment to more money for NHS services-the only commitment on financing the NHS is that it will continue to be "financed mainly out of general taxation" (my italics). Although its stated objectives, such as more audit, are welcome, the core of its proposals relate to the imposition of an untested market oriented system on the NHS. Anyone who believes that such proposals are misconceived and likely to damage the interests of patients has every reason-a duty, even - to oppose the white paper. There is nothing blind about such opposition.

Most of the contract proposals are about the way general practitioners are paid and will affect patients much less directly. Some of them certainly need to be withdrawn or modified, including the unrealistic nationwide targets for immunisation and cervical screening and the obligation to carry out health promotion activities for which there is no clear evidence of effectiveness. However, let us demonstrate how reasonable we are by negotiating on the contract while opposing the white paper.

Nottingham NG7 IQG

JOHN TEMPLE

Hewish P. NHS review: no hope in blind opposition. $\mathrm{Br}$ Med $f$ 1989;298:889-90. (1 April.)

SIR, - In view of the enormous increase in the information that we expect to receive from the information revolution proposed in the white paper, I though I ought to let you know of the current state of affairs as regards information for plastic surgery.

A patient recently asked me where he could obtain the quickest plastic surgical appointment. My secretary rang the Department of Health, which told us that it did not have the information. My patient wrote to the department, which suggested that he should write to the various regional health authorities in England to give him a list.

I asked him to do so; the results are presented in the table. The information took my secretary, me, and my patient about three months to accumulate. I am now fearful that in future we will have to write to each individual region and hospital

Waiting lists for plastic surgery in regional and district health authorities in England

Waiting time

(weeks ${ }^{\star}$

\begin{tabular}{lc} 
South West Thames: & \\
$\begin{array}{l}\text { Queen Mary's Hospital } \\
\text { St George's Hospital }\end{array}$ & \\
East Angliant & $2-5$ \\
Mersey: & 4 \\
Outpatient & \\
Inpatient & \\
West Midlandst: & 21 \\
Dudley & 69 \\
North Warwickshire & \\
Coventry and Warwickshire Hospital & $6-24$ \\
North East Thames & $9-10$ \\
South East Thames: & $5-20$ \\
King's College Hospital & 16 months \\
Surgery & \\
Guy's Hospital & $0-33$ \\
$\quad$ Surgery & 20 \\
Salisbury & $0-5$ \\
Surgery & 107 \\
North West Thames & 12 \\
\hline
\end{tabular}

«Unless stated otherwise

†Doctor asked to write for information. to find out not only their waiting lists but also the particular costs of each treatment that we require for our patients.

London SE24 8SX

DAVID STEPPHENS

SIR,-Like Dr A Morgan and others' we are general practitioners in London who are enthusiasts for health promotion. We regard their enthusiasm for the new contract for general practitioners, however, as both naive and ill thought out.

The central drive of the contract-that is, a sharp increase in the element deriving from capitation - is thoroughly retrograde. It will force list size up and consultation time down. Singlehanded colleagues will be driven to extensive nonNHS work to maintain their income, and incoming vacancies will become still rarer. The target figures for vaccination and cervical cytology are simply unobtainable in inner cities given the problem of list inflation, patient turnover, and ethnic minorities. Indeed, it seems to us quite extraordinary that anyone with a knowledge of modern urban practice would ever draft such proposals. The contract itself is wedded to the white paper's philosophy of competitive marketplace care, which is an inappropriate and inefficient method of health care provision. Inner city doctors like ourselves are likely to be especially penalised by the white paper's plans as hospitals opting out will probably leap frog over us and our patients to do business with megapractices holding budgets in the affluent south east. The community health services, which we find so valuable in health promotion, would be marginalised by the white paper's proposals.

The contract for general practitioners needs to be developed, and a few of the features in the proposed draft, such as an allowance for socia deprivation, are appropriate. ${ }^{2}$ But the philosophies of the present draft, its effect on general prac titioners' income and terms of service, and the arrogant manner in which it is being imposed are unacceptable.

DAVID WIDGERY FELICITY CHALLONER

London E14 8HQ ANNA LIVINGSTONE

Morgan A, Bower P, Barnard S, Bird C. NHS review. Br Med 1989;298:747. (18 March.)

Widgery DJ. The national health. London: Hogarth, 1988:78-81.

\section{Enhanced transmission of HIV to women in South Africa}

SIR, - The editorial by Professor D C G Skegg focused on the transmission dynamics of HIV infection and rightly emphasised the importance of sexually transmitted diseases and genital ulceration in enhancing virus transmission and their role in accounting for the varying rates of transmission found in different heterosexual risk groups.

In the sexually transmitted diseases clinic attached to this hospital about 6000 black patients with genital ulceration are seen each year. A recent survey of 100 men and 100 women with genital ulceration showed the men to have had more sexual partners over the three month period before their attendance at the clinic, the men admitting to a total of 190 partners (range $0-7$ ) and the women to 114 (range 0-3). Recurrent attenders at the clinic and patients with genital ulceration were offered HIV antibody testing with consent from July 1988 to January 1989 . The overall antibody prevalence was $2 \cdot 5 \%(62 / 2461), 2 \cdot 1 \%$ of men $(32 / 1524)$ and $3 \cdot 2 \%$ of women $(30 / 937)$ being seropositive, giving a ratio of men to women of $1: 1 \cdot 5$.

Sexually active men and women are generally affected by HIV infection in about equal propor- tions in sub-Saharan Africa, ${ }^{2}$ although an excess of female patients with AIDS was found in Ghana in 1986 after repatriation of prostitutes from neighbouring countries. Our study, however, shows a higher prevalence of HIV antibody in women even though no prostitutes were identified. This may be accounted for by the higher transmission rate of the virus from men to women.

Prostitutes and patients with genital ulceration are recognised risk groups for both infection with and transmission of HIV, and our studies sugges that, just as female prostitutes represent a foca group for spread of HIV infection into the male community, so may HIV positive men with genital ulceration and many sexual partners represent a key group for spread into the female population in our area.

Health education, counselling, and providing condoms for patients with genital ulceration should now be regarded as a priority.

NIGEL O'FARRELL. ISOBEL WINUSOR

City Health Department Sexually

Transmitted Diseases Clinic and

Department of Virology,

King Edward VIII Hospital,

Congella, Durban 4013

South Africa

Skegg DCG. Heterosexually acquired HIV infection. $\mathrm{Br}$ Med $\mathcal{f}$ 1989;298:401-2

2 Anonymous. AIDS in sub-Saharan Africa. [Editorial.] Lancet $1988 ; \mathrm{i}: 1260-1$

3 Neequaye AR, Neequaye J, Mingle JA, Adjei DO. Preponderance of females with AIDS in (ihana. Lancet 1986;ii:978.

\section{Iron deficiency in adolescents}

SIR,-Iron deficiency in children has been the subject of much recent interest following reports of impaired intellect and behaviour in children with iron deficiency reversed by treatment with iron, and Dr Paul Armstrong has now found a high prevalence of iron depletion among Irish adolescents. ${ }^{2}$ Recent British studies have shown high levels of iron deficiency in young children in hospital or areas with a large proportion of Asian families. ${ }^{3}+$ In a study aimed at defining the prevalence of iron deficiency in white children and exploring the effects of economic deprivation we found unexpected results.

We studied children aged 9-15 months attending baby clinics in two areas of Newcastle, one an affluent suburb, the other a deprived inner city area. Capillary blood $(0.25 \mathrm{ml})$ was collected from the great toe into a bottle containing edetic acid, and haematological variables were measured by Coulter counter. A blood film was examined and haemoglobin electrophoresis performed. Lower limits of normal for haemoglobin, mean cell volume, and mean cell haemoglobin were defined as the third centile,' ${ }^{\circ}$ and iron deficiency was defined as subnormal mean cell volume or mean cell haemoglobin with an otherwise normal blood film and electrophoresis.

Children from the two areas showed the same age distribution, but the "deprived" children were significantly more likely to have had low birth weight, a hospital admission, or an unemployed parent. There was no significant difference in the haematological findings between the two areas (table). The overall prevalence of anaemia (13.5\%) was similar to that found in other studies, ${ }^{34}$ but cell variables suggestive of iron deficiency were seen in many fewer cases $(3 \cdot 5 \%$ overall). The correlation between iron deficiency and anaemia was poor; of the five children with subnormal mean cell volume and mean cell haemoglobin, three had a normal haemoglobin, and of the 19 with low haemoglobin only two had mean cell volumes or haemoglobin values suggestive of iron deficiency. Direct measures of iron stores were not available, but seven of the 19 children with apparent anaemia had mean cell values above the median, making iron 